DOI 10.15593/2224-9354/2018.3.26

УДК 338.342:658.114-022.51

\title{
О.Я. Старкова
}

\section{РЕГИОНАЛЬНЫЙ АСПЕКТ ПОДДЕРЖКИ МАЛОГО БИЗНЕСА В СЕЛЬСКОМ ХОЗЯЙСТВЕ}

\begin{abstract}
Рассмотрена роль малого бизнеса в обеспечении продовольственной безопасности Российской Федерации. Определена роль сельского хозяйства в условиях экономических санкций. Перечислены типы государственной агарной политики и ее значение. Дана классификация видов эффективности государственной поддержки. Определены целевые показатели эффективности государственной поддержки в сельском хозяйстве. Приведен пример региональной методики определения эффективности государственных программ. Дана характеристика нестандартной занятости, в рамках которой осуществляют свою деятельность крестьянские (фермерские) хозяйства. Названы преимущества малого бизнеса по сравнению с крупными предприятиями. Рассмотрены недостатки малого бизнеса и способы их преодоления. Определены необходимые условия для развития аграрного малого бизнеса. Перечислены меры адаптации деятельности малого бизнеса в условиях присоединения к ВТО. Рассмотрена опасность излишней концентрации производства в крупных компаниях. Названы целевые показатели развития малого бизнеса в Стратегии устойчивого развития сельских территорий. Проведен анализ количества крестьянских (фермерских) хозяйств $(К(\Phi) X)$ и индивидуальных предпринимателей (ИП) в аграрной сфере Пермского края и обеспеченность их земельными ресурсами. Сделан вывод об ограниченности земельных ресурсов у малого бизнеса Пермского края по сравнению с Российской Федерацией в целом и Приволжским федеральным округом, а также сделан вывод о наращивании производства основных видов сельскохозяйственной продукции К(Ф)Х и ИП. Определены недостатки региональной поддержки развития агарного малого бизнеса и внесены предложения по ее совершенствованию.

Ключевые слова: продовольственная безопасность, государственная поддержка, субсидирование, крестьянские (фрермерские) хозяйства, индивидуальные предприниматели.
\end{abstract}

Введение. Продовольственное эмбарго, обострило вопрос безопасности Российской Федерации в сфере обеспечения продуктами питания населения страны. Роль сельского хозяйства заметно выросла, так как состоит в настоящее время не только в поддержании продовольственной безопасности, но и в обеспечении сбалансированного экономического роста. А.А. Быков и Т.В. Хвалько признают сбалансированным такой рост ВВП, который обеспечивает положительное внешнеторговое сальдо, равновесие на финансовых рынках, отсутствие бюджетного дефицита, снижение уровня инфляции [1, с. 5].

Сельское хозяйство достаточно успешно справляется с поставленными задачами, что было бы невозможно без налогового стимулирования и субсидирования производства [2, с. 87]. 3.Б. Алиева выделяет четыре типа аграрной политики, первая из которых направлена на поддержку сельского хозяй-

(С) Старкова О.Я., 2018

Старкова Ольга Яковлевна - канд. экон. наук, доцент кафедры бухгалтерского учета и финансов ФГБОУ ВО «Пермский государственный аграрно-технологический университет им. акад. Д.Н. Прянишникова», доцент кафедры финансов, кредита и биржевого дела ФГБОУ ВО «Пермский государственный национальный исследовательский университет», e-mail: klimova377@mail.ru. 
ства, а остальные три - на поддержку производства средств производства, поддержку аграрной науки и т.д. [3, с. 34].

В условиях ограниченности бюджетных ресурсов наиболее актуальным становится эффективное их использование. Н.И. Пыжикова, Е.В. Титова и М.А. Козлов под эффективностью понимают степень достижения цели при максимальном использовании условий и факторов [4]. Данные авторы предлагают использовать классификацию видов эффективности государственной поддержки. По их мнению, экономические результаты отражают эффективность государственной экономической политики, а социальные - эффективность решения социальных проблем. Эффективность государственной поддержки в сельском хозяйстве имеет свои особенности и определяется целевыми показателями: индексом производства сельскохозяйственной продукции, индексом физического объема инвестиций, индексом производительности труда и т.д. [4, с. 5]. Оценка эффективности государственных программ проводится на основании Постановления Правительства РФ от 2 августа 2010 года № 588. Регионы разрабатывают собственные методики определения эффективности, например, в Ставропольском крае основными критериями являются степень достижения целей программы и минимальный размер необходимых средств [5, с. 34].

Развитие сельского хозяйства базируется на принципах многоукладности, когда наряду с крупными предприятиями существуют крестьянские (фермерские) хозяйства $(К(\Phi) Х)$ и индивидуальные предприниматели. Их можно отнести к нестандартной занятости, которую Е.В. Ванкевич и О.В. Зайцева понимают как тип трудовых отношений, характеризующийся многообразием форм заключаемых трудовых сделок, включающих самостоятельную занятость, сверхзанятость, недозанятость [6, с. 131]. Действительно, К(Ф)Х могут осуществлять производство, не привлекая наемных работников.

Малый бизнес имеет свои преимущества перед крупными предприятиями. Н.И. Амосова и Е.Г. Вяльцев отмечают его гибкость, оперативность при принятии решений, восприимчивость к новшествам, высокий уровень специализации производства и труда [7, с. 20]. Д.О. Свиридов дополняет данные преимущества следующими: готовность к риску, более высокая интенсивность труда и заинтересованность в его результатах [8, с. 120].

Наряду с достоинствами малому бизнесу свойственны и недостатки. К таковым А.А. Головнин относит сложность выхода на торговые сети, низкий объем производства, слабая инвестиционная привлекательность для банков. Данные недостатки преодолимы за счет кооперации и развития договорных отношений [9, с. 28]. Высокие требования банков к малому сектору агропроизводства отмечает и Е.В. Капелист [10, с. 140].

Для развития аграрного малого бизнеса, как считают В.М. Секачева, О.В. Оскирко и М.Б. Скарюпина, необходима оптимизация налогообложения $[11$, c. 1027]. Что касается налогообложения, то можно утверждать, что сель- 
ский малый бизнес имеет большие налоговые преимущества перед другими налогоплательщиками [12, с. 67].

Присоединение Российской Федерации к ВТО требует, по мнению В.Н. Павлова, особых мер адаптации малого бизнеса к новым условиям, включающим оценку потерь, защиту интересов российских производителей [13, с. 56].

Для преодоления отмеченных сложностей Е.В. Лактюшина предлагает создать благоприятную нормативно-правовую базу и социально-экономические условия для развития кредитной и закупочно-сбытовой кооперации [14, с. 90].

Высоко оценивая роль малого бизнеса в аграрном производстве, трудно не согласиться с предостережением, высказанным Ю.В. Бабиной относительно излишней концентрации производства в крупных компаниях [15, с. 189]. Развитие малого бизнеса - это «подушка безопасности» экономики страны [16, с. 97].

Целью данного исследования является определение места и роли малого бизнеса в сельском хозяйстве Пермского края и эффективности государственной поддержки его развития.

Объекты и методы исследования. Объектом исследования является аграрный малый бизнес Пермского края. При написании статьи нашел применение монографический метод исследования для комплексно-функционального анализа изучения взаимосвязей с помощью аналитических показателей.

Результаты и обсуждения. Малый бизнес в сельском хозяйстве представлен крестьянскими (фермерскими) хозяйствами и индивидуальными предпринимателями. В соответствии со Стратегией устойчивого развития сельских территорий Российской Федерации к 2030 году доля крестьянских (фермерских) хозяйств и индивидуальных предпринимателей в производстве сельскохозяйственной продукции должна составить $20 \%$ и среднегодовые темпы прироста их производства достигнуть 5,5 \%. Рассмотрим, насколько достижимы данные цели для малого бизнеса Пермского края.

Количество К(Ф)Х и ИП, а также общая земельная площадь в расчете на одно хозяйство отражено в табл. 1 [17, с. 28-31].

Таблица 1

Крестьянские (фермерские) хозяйства и индивидуальные предприниматели в сельском хозяйстве в 2016 году

\begin{tabular}{|l|c|c|c|}
\hline \multicolumn{1}{|c|}{ Показатель } & Российская Федерация & ПФО & Пермский край \\
\hline \multicolumn{4}{|c|}{ Крестьянские (фермерские) хозяйства } \\
\hline Число хозяйств & 136558 & 23004 & 1262 \\
\hline $\begin{array}{l}\text { Земельная площадь } \\
\text { на 1 хозяйство, га }\end{array}$ & 268,9 & 373,9 & 96,4 \\
\hline \multicolumn{4}{|c|}{ Индивидуальные предпиниматели } \\
\hline Число хозяйств & 38026 & 5556 & 309 \\
\hline $\begin{array}{l}\text { Земельная площадь } \\
\text { на 1 хозяйство, га }\end{array}$ & 140,0 & 195,4 & 53,4 \\
\hline
\end{tabular}


Анализируя данные табл. 1, можно сказать, количество К(Ф)Х в Российской Федерации в 2016 году в 3,6 раза превосходило количество ИП, занимающихся сельским хозяйством. Количество К(Ф)Х ПФО составило в данный период 16,8\% от общего количества, находящихся в РФ. В Пермском крае количество К(Ф)Х составило 1262 единицы, или 5,5 \% от их количества в ПФО. Фермерские хозяйства ПФО в целом располагают большей земельной площадью, приходящейся на одно хозяйство по сравнению с РФ на $28 \%$. В Пермском крае земельные ресурсы фермеров меньше, чем в РФ в 2,8 раза. Земельные площади, которыми располагают ИП, меньше по сравнению с земельными площадями К(Ф)Х почти в два раза. Наименьшими земельными угодьями владеют ИП в Пермском крае, их площадь составляет 53,4 га в среднем на одно хозяйство. Земельные площади обеспечивают производство аграрной продукции (табл. 2) [17, с. 97].

Таблица 2

Производство продукции крестьянскими (фермерскими) хозяйствами и индивидуальными предпринимателями в Пермском крае в 2012-2016 годах, тыс. т

\begin{tabular}{|l|c|c|c|c|c|}
\hline \multicolumn{1}{|c|}{ Продукция } & 2012 & 2013 & 2014 & 2015 & 2016 \\
\hline Зерно & 17,4 & 14,9 & 25,6 & 27,3 & 22,6 \\
\hline Картофель & 18,7 & 18,0 & 23,0 & 23,2 & 22,9 \\
\hline Овощи & 5,7 & 7,8 & 8,6 & 9,5 & 11,3 \\
\hline Скот и птица & 1,4 & 1,6 & 2,0 & 2,1 & 2,3 \\
\hline Молоко & 6,3 & 7,3 & 10,3 & 12,6 & 15,9 \\
\hline Яйца, млн шт. & 8,2 & 12,5 & 14,3 & 15,2 & 18,2 \\
\hline Шерсть, т & 5 & 6 & 5 & 10 & 10 \\
\hline Мед, т & 72 & 92 & 115 & 59 & 111 \\
\hline
\end{tabular}

Данные табл. 2 подтверждают, что производство всех видов продукции К(Ф)Х и ИП в Пермском крае увеличилось. Производство животноводческой продукции наращивалось ежегодно и за период выросло в среднем почти в два раза. Растениеводство в большей степени зависит от погодных условий, поэтому объем производства данной отрасли вырос только в 1,5 раза.

Рост производства привел к увеличению доли К(Ф)Х и ИП в общей структуре производства продукции (табл. 3) [17, с. 98].

За период с 2012 по 2016 год доля малого бизнеса в производстве аграрной продукции в Пермском крае выросла по всем основным видам продукции. Наибольший вклад им внесен в производство шерсти, что составило более $20 \%$, достаточно значительна доля в производстве зерна $(9,2 \%)$ и меда $(7,1 \%)$. В целом доля К(Ф)Х и ИП в производстве продукции сельского хозяйства выросла (табл. 4) [17, с. 96]. 
Доля крестьянских (фермерских) хозяйств и индивидуальных предпринимателей в производстве продукции в Пермском крае в 2012-2016 годах, \%

\begin{tabular}{|l|c|c|c|c|c|}
\hline \multicolumn{1}{|c|}{ Продукция } & 2012 & 2013 & 2014 & 2015 & 2016 \\
\hline Зерно & 5,4 & 5,4 & 7,0 & 9,0 & 9,2 \\
\hline Картофель & 3,1 & 3,2 & 4,3 & 4,6 & 4,6 \\
\hline Овощи & 2,5 & 3,3 & 3,8 & 4,3 & 4,9 \\
\hline Скот и птица & 1,8 & 2,1 & 2,6 & 2,6 & 3,1 \\
\hline Молоко & 1,3 & 1,6 & 2,2 & 2,6 & 3,3 \\
\hline Яйца & 0,8 & 1,3 & 1,4 & 1,4 & 1,6 \\
\hline Шерсть & 11,1 & 11,5 & 10,6 & 20,8 & 20,4 \\
\hline Мед & 5,2 & 5,9 & 6,8 & 6,7 & 7,1 \\
\hline
\end{tabular}

Таблица 4

Доля сельхозпродукции различных типов хозяйств Пермского края, \%

\begin{tabular}{|l|c|c|c|c|c|}
\hline \multicolumn{1}{|c|}{ Тип хозяйства } & 2012 г. & 2013 г. & 2014 г. & 2015 г. & 2016 г. \\
\hline Хозяйства всех категорий & 100 & 100 & 100 & 100 & 100 \\
\hline К(Ф)Х и ИП & 2,4 & 2,8 & 3,8 & 4,1 & 4,9 \\
\hline
\end{tabular}

За период с 2012 по 2016 год доля малого бизнеса в производстве агарной продукции Пермского края выросла с 2,4 до 4,9\%, т.е. рост составил в среднем за год около 0,5 \%. Однако для достижения целевых показателей Стратегии необходимо обеспечить ежегодный рост этого показателя на 1,1\%.

Другим важнейшим показателем, определенным Стратегией, являются индексы производства (табл. 5) [17, с. 96].

Таблица 5

Индексы производства продукции сельского хозяйства, \%

\begin{tabular}{|l|c|c|c|c|c|}
\hline \multicolumn{1}{|c|}{ Тип хозяйства } & 2012 г. & 2013 г. & 2014 г. & 2015 г. & 2016 г. \\
\hline Хозяйства всех категорий & 94,2 & 96,6 & 100,9 & 98,6 & 99,6 \\
\hline К(Ф)Х и ИП & 107,1 & 117,6 & 134,2 & 111,2 & 117,1 \\
\hline
\end{tabular}

Индексы производства продукции сельского хозяйства в Пермском крае не подтверждают существующее мнение о том, что продовольственное эмбарго обеспечило рост сельского хозяйства. В 2015-2016 годах имеет место снижение производства продукции в хозяйствах всех категорий. Следовательно, только ограничением импорта сельскохозяйственных товаров продовольственную безопасность Пермского края обеспечить не удается. Необходима эффективная государственная агарная политика по поддержке отечественного производителя. 
Рост производства демонстрируют крестьянские (фермерские) хозяйства и индивидуальные предприниматели, этот рост составил в среднем 17 \% в год, что превосходит ориентиры, определяемые Стратегией. Таким образом, именно малому бизнесу в сельском хозяйстве Пермского края региональные органы власти должны уделять повышенное внимание и оказывать адекватную поддержку.

Данная поддержка осуществляется в соответствии с Государственной программой Пермского края «Развитие сельского хозяйства и устойчивое развитие сельских территорий в Пермском крае». Финансирование программы осуществляется за счет средств Федерального бюджета и бюджета Пермского края. Исполнение Государственной программы в 2016 году составило 97,6 \% от плановых показателей. В источниках финансирования программы преобладают средства бюджета Пермского края, доля которых составляет 59 \%. Однако почти 4 \% этих средств не было использовано, а следовательно, часть расходов не была профинансирована.

В рамках программы существует подпрограмма «Поддержка малых форм хозяйствования», средства которой в 2016 году были использованы не полностью на сумму 8374,4 тыс. руб. (табл. 6).

Таблица 6

Неиспользованные средства субсидий подпрограммы «Поддержка малых форм хозяйствования»

в Пермском крае в 2016 году

\begin{tabular}{|l|c|c|}
\hline \multicolumn{1}{|c|}{ Назначение субсидии } & Сумма, тыс. руб. & Уд. вес, \% \\
\hline Развитие семейных животноводческих ферм & 3655,8 & 43,7 \\
\hline Поддержка молодых фермеров & 2735,0 & 32,6 \\
\hline Возмещение части ставки по кредитам & 1885,9 & 22,5 \\
\hline Возмещение части затрат при оформлении земли & 97,7 & 1,2 \\
\hline В с е г & 8374,4 & 100 \\
\hline
\end{tabular}

Поддержка малых форм хозяйствования на земле осуществляется путем предоставления субсидий, направляемых на софинансирование целевых расходов. Большая часть субсидий (76,3 \%) была предназначена для создания или развития фермерских хозяйств. Для Пермского края данное направление является очень важным, так как именно крестьянские (фермерские) хозяйства и индивидуальные предприниматели наращивают производство. Малый бизнес часто сталкивается с недостатком источников финансирования и ему приходится прибегать к банковским кредитам. Государство субсидирует часть ставки по банковским кредитам, делая их более доступными. Однако в 2016 году в Пермском крае 1885,5 тыс. руб., предназначенные на софинансирование процентной ставки, не были использованы малым бизнесом, значит, часть проектов не была реализована. Для Пермского края крайне острой является проблема обеспечения земельными ресурсами малого бизнеса, так как 
средний размер их земельных угодий почти в 4 раза меньше, чем в ПФО. Однако субсидии, предназначенные на возмещение части затрат при оформлении в собственность земли на сумму 97,7 тыс. руб., не были использованы. Причины неполного использования субсидий связаны с непредоставлением заявок или расчетов на субсидии либо предоставлением документов, не отвечающих требованиям.

Несмотря на недофинансирование расходов по поддержке малых форм хозяйствования, целевые показатели подпрограммы в 2016 году оказались выполнены или даже перевыполнены, что говорит о том, что планируются меньшие результаты, чем те, которые могли бы быть достигнуты.

Bbыводы. Малый бизнес в сельском хозяйстве играет очень важную роль, не только обеспечивая продовольственную безопасность Российской Федерации, но и являясь хранителем национальной культуры и традиций. Государственная агарная политика предусматривает особые меры поддержки крестьянских (фермерских) хозяйств и индивидуальных предпринимателей, включая использование специальных налоговых режимов, получение субсидий и грантов на развитие хозяйства. Аграрный малый бизнес в Пермском крае увеличивает производство сельскохозяйственной продукции, тогда как другие формы хозяйствования не могут это обеспечить. Однако фермеры и предприниматели сталкиваются с рядом проблем, часть из которых может быть решена с помощью государственной поддержки. Для повышения эффективности использования бюджетных ресурсов необходимо: перераспределить финансирование в пользу малого бизнеса пропорционально получаемой отдаче от вложений; повысить качество бюджетного планирования; облегчить процедуру получения субсидий, улучшив качество информационных и консультационных услуг региональными и местными органами власти.

\section{Список литературы}

1. Быков А.А., Хвалько Т.В. Вклад отраслей в сбалансированный рост белорусской экономики // Белорусский экономический журнал. - 2017. № 2. - С. 4-20.

2. Старкова О.Я. Конкуренция и государственная поддержка как условия развития аграрного сектора экономики // Пермский агарный вестник. 2015. - № 3(9). - С. 86-91.

3. Алиева 3.Б. Роль финансово-кредитных инструментов в оптимизации аграрной политики // Финансы: теория и практика. - 2017. - Т. 21, № 2(98). C. $30-43$.

4. Пыжикова Н.И., Титова Е.В., Козлов М.А. Критерии оценки эффективности государственной поддержки малого и среднего бизнеса АПК Красноярского края // Успехи современной науки. - 2015. - № 3. - С. 5-7. 
5. Айдинова А.Т. Этапы развития программ господдержки малого бизнеса на селе и оценки их эффективности // Экономика: вчера, сегодня, завтра. 2016. - № 2. - С. 27-42.

6. Ванкевич Е.В., Зайцева О.В. Нестандартная занятость: сущность, формы, масштабы регулирования // Белорусский экономический журнал. 2015. - № 3. - С. 129-149.

7. Амосова Н.И., Вяльцев Е.Г. Проблемы функционирования среднего и малого бизнеса в АПК Курганской области // Инновационная наука. - 2016. № 4. - С. 20-23.

8. Свиридов Д.О. Инновационное развитие малого бизнеса в АПК // Социально-экономические явления и процессы. - 2016. - Т. 11, № 12. С. 119-124.

9. Головнин А.А. Формирование устойчивой среды функционирования малых форм хозяйствования в АПК на основе развития договорных отношений // Вестник Курской государственной сельскохозяйственной акдемии. 2016. - № 7. - С. 27-31.

10. Капелист Е.В. Малый и средний бизнес в АПК: направления и специфика дифференцированной государственной поддержки // Евразийский союз ученых. - 2015. - № 4-1(13). - С. 139-140.

11. Секачева В.М., Оскирко О.В., Скарюпина М.Б. Развитие малого бизнеса в АПК как одного из элементов институциональных преобразований экономики региона // АПК России. - 2016. - Т. 23, № 5. - С. 1027-1036.

12. Старкова О.Я. Государственное регулирование инновационного развития сельскохозяйственного производства // Пермский агарный вестник. 2015. - № 3(11). - С. 65-69.

13. Павлов В.Н. Адаптация российского малого бизнеса к вступлению в ВТО // Вестник Саратовского государственного социально-экономического университета. - 2015. - № 3(57). - С. 54-56.

14. Лактюшина Е.В. К вопросу о дифференциации в развитии крестьянских (фермерских) хозяйств // Вестник АПК Верхневолжья. - 2015. № 1(29). - С. 86-91.

15. Бабина Ю.В. Влияние кризиса на инвестиционный климат развития малого и среднего бизнеса в аграрном секторе // Вестник Новосибирского государственного аграрного университета. - 2015. - № 4(47). С. $188-193$.

16. Чистякова М.К. Малый бизнес в сфере АПК: проблемы развития на современном этапе // Вестник сельского развития и социальной политики. 2017. - № 3(15). - С. 97-99.

17. Пермский край в цифрах 2017: крат. стат. сб. / Террит. орган Федер. службы гос. статистики по Пермскому краю. - Пермь, 2017. - 180 с. 


\section{References}

1. Bykov A.A., Khval'ko T.V. Vklad otraslei $\mathrm{v}$ sbalansirovannyi rost belorusskoi ekonomiki [Contribution of sectors to the balanced growth of the Belarusian economy]. Belarusian Economic Journal, 2017, no. 2, pp. 4-20.

2. Starkova O.Ia. Konkurentsiia i gosudarstvennaia podderzhka kak usloviia razvitiia agrarnogo sektora ekonomiki [Competition and state aid as a condition for development of the agricultural sector]. Perm Agrarian Journal, 2015, no. 3(9), pp. 86-91.

3. Alieva Z.B. Rol' finansovo-kreditnykh instrumentov v optimizatsii agrarnoi politiki [The role of financial and credit tools in optimization of agrarian policy]. Finance: Theory and Practice, 2017, vol. 21, no. 2(98), pp. 30-43.

4. Pyzhikova N.I., Titova E.V., Kozlov M.A. Kriterii otsenki effektivnosti gosudarstvennoi podderzhki malogo i srednego biznesa APK Krasnoiarskogo kraia [Criteria of evaluating of the effictiveness of small and medium business public support in agriculture of Krasnoyarsk region]. Modern Science Success, 2015, no. 3, pp. 5-7.

5. Aidinova A.T. Etapy razvitiia programm gospodderzhki malogo biznesa na sele i otsenki ikh effektivnosti [The stages in the development of state-supported programs for small business in rural areas and the assessment of their effectiveness]. Economics: Yesterday, Today and Tomorrow, 2016, no. 2, pp. 27-42.

6. Vankevich E.V., Zaitseva O.V. Nestandartnaia zaniatost': sushchnost', formy, masshtaby regulirovaniia [Non-standard employment: essence, forms, size and regulation]. Belarusian Economic Journal, 2015, no. 3, pp. 129-149.

7. Amosova N.I., Vial'tsev E.G. Problemy funktsionirovaniia srednego i malogo biznesa v APK Kurganskoi oblasti [Problems of functioning of small and medium business in agriculture of Kurgan region]. Innovatsionnaia nauka, 2016, no. 4 , pp. 20-23.

8. Sviridov D.O. Innovatsionnoe razvitie malogo biznesa v APK [Innovative development of small business in AIC]. Sotsial'no-ekonomicheskie iavleniia $i$ protsessy, 2016, vol. 11, no. 12, pp. 119-124.

9. Golovnin A.A. Formirovanie ustoichivoi sredy funktsionirovaniia malykh form khoziaistvovaniia $\mathrm{v}$ APK na osnove razvitiia dogovornykh otnoshenii [Formation of a stable environment of functioning of small forms of managing farming in agrarian and industrial complex on the basis of contractual relations]. Vestnik of Kursk State Agricultural Academy, 2016, no. 7, pp. 27-31.

10. Kapelist E.V. Malyi i srednii biznes v APK: napravleniia i spetsifika differentsirovannoi gosudarstvennoi podderzhki [Small and medium business in agriculture: trends and specificity of the differentiated state support]. Eurasian Union of Scientists, 2015, no. 4-1(13), pp. 139-140. 
11. Sekacheva V.M., Oskirko O.V., Skariupina M.B. Razvitie malogo biznesa v APK kak odnogo iz elementov institutsional'nykh preobrazovanii ekonomiki regiona [Small business development in agriculture as one of the elements of the institutional transformations of the region economy]. Agro-Industrial Complex of Russia, 2016, vol. 23, no. 5, pp. 1027-1036.

12. Starkova O.Ia. Gosudarstvennoe regulirovanie innovatsionnogo razvitiia sel'skokhoziaistvennogo proizvodstva [State regulation of innovative development of agricultural production]. Perm Agrarian Journal, 2015, no. 3(11), pp. 65-69.

13. Pavlov V.N. Adaptatsiia rossiiskogo malogo biznesa k vstupleniiu v VTO [Adaptation of small businesses to join WTO]. Vestnik of Saratov State SocioEconomic University, 2015, no. 3(57), pp. 54-56.

14. Laktiushina E.V. K voprosu o differentsiatsii v razvitii krest'ianskikh (fermerskikh) khoziaistv [To a question on differentiation in development of farms]. Vestnik APK Verkhnevolzh'ia, 2015, no. 1(29), pp. 86-91.

15. Babina Iu.V. Vliianie krizisa na investitsionnyi klimat razvitiia malogo i srednego biznesa $\mathrm{v}$ agrarnom sektore [Crisis and its influence on investment environment of middle and small agricultural entreprises]. Bulletin of Novosibirsk State Agrarian University, 2015, no. 4(47), pp. 188-193.

16. Chistiakova M.K. Malyi biznes v sfere APK: problemy razvitiia na sovremennom etape [Small business in the sphere of the APK: problems of development at the present stage]. Vestnik sel'skogo razvitiia i sotsial'noi politiki, 2017, no. 3(15), pp. 97-99.

17. Permskii krai v tsifrakh 2017: kratkii statisticheskii sbornik [Perm Krai in figures. 2017. Brief statistical yearbook]. Perm, Federal State Statistics Service of Perm region, 2017, $180 \mathrm{p}$.

Оригинальность $86 \%$

Получено 05.02.2018 Принято 12.03.2018 Опубликовано 28.09.2018

\author{
O.Ya. Starkova
}

\title{
THE REGIONAL ASPECT OF SUPPORTING SMALL BUSINESS IN AGRICULTURE
}

\begin{abstract}
The article reveals the role of small business in ensuring food security of the Russian Federation. The role for agriculture in the face of economic sanctions is identified. The types of the state agrarian policy and its value are listed. The classification of state support efficiency types is considered. The target values of state support efficiency in agriculture is determined. An example of a regional methodology for determining the efficiency of state programs is given. The characteristics of non-standard employment with which peasant farms operate is given. The advantages of small business compared to large enterprises are mentioned. Disadvantages of small business and ways to overcome them are
\end{abstract}


considered. The conditions necessary for development of agrarian small businesses is determined. The adaptation measures of small business activities in conditions of WTO accession are discussed. The risk of excessive production concentration in large companies is considered. The goals for development of small business in the strategy of sustainable development of rural teritories are named. The analysis of the number of (peasant) farms and individual entrepreneurs in the agricultural sector of Perm territory and their access to land resources per farm is made. A conclusion is made about limited land resources in small business of Perm Krai in comparison with the Russian Federation as a whole and the Volga Federal district. A growing output of the main agricultural products produced by peasant farms and individual entrepreneurs is found. The disadvantages of regional support for the development of agrarian small businesses are identified and suggestions for its improvement are offered.

Keywords: food security, state support, subsidies, private (peasant) farms, individual entrepreneurs.

Olga Ya. Starkova - Candidate of Economic Sciences, Associate Professor, Department of Accounting and Finance, Perm State Agro-Technological University; Associate Professor of the Department of Finance, Credit and Stock Exchange, Perm State National Research University, e-mail: klimova377@mail.

\section{Received 05.02.2018 Accepted 12.03.2018 Published 28.09.2018}

